\title{
Association between body mass index and macronutrients differs along the body mass index range of German adults: results from the German National Nutrition Survey II
}

\author{
Kilson Moont, Carolin Krems*, Thorsten Heuer and Ingrid Hoffmann \\ Department of Nutritional Behaviour, Max Rubner-Institut, Federal Research Institute of Nutrition and Food, Haid-und-Neu-Str. 9 , 76131 \\ Karlsrube, Germany \\ (Received 30 July 2020 - Final revision received 3 December 2020 - Accepted 21 December 2020)
}

Journal of Nutritional Science (2021), vol. 10, e8, page 1 of 8

doi:10.1017/jns.2020.60

Abstract

The aim of the present study was to determine whether the association between body mass index (BMI) and the intake of macronutrients varies along the BMI distribution of German adults. Based on a sample of 9214 men and women aged $18-80$ years from the representative cross-sectional German National Nutrition Survey (NVS) II, quantile regression was used to investigate the association between BMI and the intake of macronutrients independent of energy intake and other predictors. In both sexes, BMI was positively associated with the intake of total protein and animal protein over its entire range and negatively associated with vegetable protein. A negative association between BMI and the intake of polysaccharides was found along the entire range of BMI in men. There was a weak negative association between BMI and the intake of total fat and saturated fatty acids observed in normalweight-range women only. In conclusion, the association between BMI and the intake of macronutrients varies along the BMI range. Animal protein intake is positively associated with BMI independent of energy intake in both sexes whereas only in men an inverse association of polysaccharide intake with BMI was shown.

Key words: BMI: Macronutrient intake: Protein intake: National Nutrition Survey II: Quantile regression

\section{Introduction}

Against the background that the high prevalence of overweight and obesity is one of the major public health problems worldwide and also in Germany, in a previous investigation based on data from the German National Nutrition Survey (NVS) II predictors of the body mass index (BMI) were analysed by including a large set of potential predictor variables. It could be demonstrated that energy intake is a strong and consistent predictor of BMI in participants who are overweight and obese, but not in individuals within the normalweight range where the association is either weak or absent ${ }^{(1)}$. The energy contributing components in the diet are fat (38 $\mathrm{kJ} / \mathrm{g})$, carbohydrates and protein $(17 \mathrm{~kJ} / \mathrm{g})$. According to the national reference values for nutrient intake, fat should contribute at maximum up to $30 \%$ of the total energy intake and more than $50 \%$ should be provided by carbohydrates ${ }^{(2)}$.

\footnotetext{
* Corresponding author: Carolin Krems, fax +49721 6625552, email carolin.krems@mri.bund.de
}

† Present address: Department Epidemiology of Health Care and Community Health, Institute for Community Medicine, University Medicine Greifswald, Ellernholzstr. 1-2, 17487 Greifswald, Germany. 
Whether the energy-generating macronutrients are associated with BMI when considering energy intake is a controversial topic in the literature with extensive literature available. Some studies show that BMI is positively associated with the intake of protein ${ }^{(3-8)}$. Other studies report that a high intake of carbohydrates ${ }^{(9,10)}$ or fat ${ }^{(6,11,12)}$ is associated with a high BMI and obesity. In addition, in some of these studies, further fractions of carbohydrates, fat or protein like animalor plant-based protein were considered. These inconsistent findings in the literature may be also due to different study designs, populations, methods and models of statistical analysis.

For example, study results could be affected by the fact that underreporters with an implausibly low energy intake were included in the data analyses. It is known that the proportion of underreporting in persons who are overweight or obese is particularly high, which diminishes the power of a study to investigate food consumption and nutrient intake ${ }^{(13)}$. In most of the studies evaluating the association between food consumption, nutrient intake and BMI, underreporters were not excluded. Another factor leading to inconsistent findings is the frequent use of BMI from self-reported body weight and height, which may be associated with reporting errors ${ }^{(14)}$. Furthermore, most of the previous studies were based on the analysis of the mean values of BMI, which does not consider the BMI range ${ }^{(3-5,8,10-12)}$. It is quite possible that the relationship between BMI and the intake of macronutrients varies along the range of BMI.

To contribute to the existing body of the literature, we applied a quantile regression model, used measured body weight and height data, and excluded individuals identified as underreporters for our analyses. Compared with conventional statistical approaches which are based on mean value analyses, the statistical model of quantile regression is robust against outliers and considers the entire BMI distribution. The aim of the present study was to determine the association between BMI and the intake of fat, carbohydrate and protein, and whether these associations varied along the BMI distribution of German adults independent of energy intake and other predictors of BMI.

\section{Material and methods}

The NVS II was a representative cross-sectional study that was carried out from November 2005 until January 2007. The study aimed to evaluate food consumption and other aspects of nutritional behaviour of the German population. Inclusion criteria for all participants were an age between 14 and 80 years, German speaking and living in private households. Participants of the NVS II were recruited by a two-stage sampling procedure. In the first stage, 500 nationwide sample points were randomly selected, and in the second stage, in each of the selected sample points, addresses were randomly drawn from the local population registries, stratified by sex and age. The response rate was $42 \%$. A detailed description of the NVS II study design and methods ${ }^{(15)}$ and the analysis of the association between BMI and its predictors using quantile regression ${ }^{(1)}$ have been previously published.

\section{Anthropometric measurements}

Body height and weight were measured with a portable Harpenden Stadiometer (Holtain Ltd., Crymych, UK) and the calibrated scale seca 862 (Seca Vogel \& Halke, Hamburg, Germany). From the measured body weight, $1 \mathrm{~kg}$ was subtracted to adjust for the weight of clothing. BMI was calculated using the formula body weight (in $\mathrm{kg}$ )/body height (in $\mathrm{m})^{2}$. In conjunction with the World Health Organization classification, participants with a BMI between 18.5 and $24.9 \mathrm{~kg} / \mathrm{m}^{2}$ are defined as normal weight, participants with a BMI between 25.0 and $29.9 \mathrm{~kg} / \mathrm{m}^{2}$ are defined as overweight and those with a BMI $30 \mathrm{~kg} / \mathrm{m}^{2}$ or higher are defined as obese ${ }^{(16)}$.

\section{Dietary assessment}

For the assessment of the usual consumption of foods and beverages over the previous 4 weeks of 15371 individuals, the dietary assessment program DISHES (Diet Interview Software for Health Examination Studies) was used ${ }^{(15,17)}$. The programme was developed and validated by the Robert Koch-Institute in Germany. At study centres, participants were asked by trained interviewers to give details of their food and beverage consumption during the preceding 4 weeks. First, information on usual meal patterns was obtained. In a next step based on this information, frequency and consumed amounts of individual food items or beverages of each meal occasion were assessed in a standardised manner. Foods which are not listed in the main screens can be searched with a text search function in the integrated German Nutrient Database. This enables to perform an open-ended interview. For quantification of consumed amounts, tableware models (cups, glasses, spoons, plates and bowls) and an excerpt of the EPIC-SOFT picture book with different portion sizes of food items were used ${ }^{(18,19)}$. To calculate dietary energy intake and the intake of total carbohydrates, mono- and disaccharides, polysaccharides, total protein, animal protein, vegetable protein, total fat, saturated fatty acids (SFA), monounsaturated fatty acids (MUFA) and polyunsaturated fatty acids (PUFA), food consumption data were matched with the German Nutrient Database (BLS 3.02) ${ }^{(20)}$.

\section{Predictors of BMI and study group}

Socio-demographic data, as well as information on time spent with sports activities, smoking status, partner relationship status and self-reported health status, were collected using a computer-assisted personal interview and a self-administered questionnaire. An index of socioeconomic status was created using school education of the participant and employment status of the principal earner of the household, which were each coded as $1=$ lowest and $8=$ highest. Additionally, net monthly income of the household, which was coded as $1=$ lowest and $9=$ highest, completed the SES index (total range 3-25). Duration of weekly sports activities like hiking, swimming or playing tennis were assessed in hours per week and summed up. Smoking status was categorised as current smoker and nonsmoker. The partner relationship status was classified as living 
with a partner and living alone. The self-reported health status of the subjects was categorised as good and fair or poor health. A more detailed description of these variables can be found in a previous publication ${ }^{(1)}$. Only subjects with complete data sets of measured body weight and height and all selected predictors of BMI were included in the analyses ( $n 13079$ from 15 371). Adolescents 14-17 years of age, pregnant and nursing women ( $n$ 1328), as well as underreporters ( $n$ 2537) identified by the method from Goldberg et al. ${ }^{(21)}$ and Black $^{(22)}$, were also excluded. Estimation of underreporting was based on the ratio of reported energy intake and resting metabolic rate which was calculated by the formula of Müller $e t a l^{(23)}$ considering sex, age and body weight. To define the proportion of low energy reporting for the applied dietary assessment method the cut-off 2 of Goldberg et al. ${ }^{(21)}$ was determined as 1.09 by inserting sample size and number of assessment days. In total, $22 \%$ of men and $21 \%$ of women were identified as underreporters with a mean BMI of $29 \cdot 0 \mathrm{~kg} / \mathrm{m}^{2}$. This resulted in a final study population of 9214 subjects who were 18-80 years of age. Due to the exclusion of several participants for the present analysis, the study sample may not be representative of the entire German population.

\section{Statistical analyses}

Quantile regression ${ }^{(24)}$ was applied to analyse the association between BMI and the intake of total carbohydrates, monoand disaccharides, polysaccharides, total protein, animal protein, vegetable protein, total fat, SFA, MUFA and PUFA taking into consideration the following predictors: energy intake, age, sports activities, socioeconomic status, smoking habits, partner relationship status and self-reported health status. The conditional quantile functions at different quantiles were estimated from the 5th to 95 th quantile with $5 \%$ distance. For each macronutrient, a separate regression model was applied because of multicollinearity among the different macronutrients. In each regression model, the dependent variable was BMI and the independent variable was the intake of the selected macronutrient, which was adjusted for the other predictors. The quantile regression was carried out using PROC QUANTREG in SAS Version 9.3 (SAS Institute, Cary, NC, USA). A Bonferroni correction was used to adjust for multiple comparisons. Thus, the $P$-value threshold was $0 \cdot 005(0 \cdot 05 / 10)$. A Markov chain marginal bootstrap was used to calculate confidence intervals for quantiles.

\section{Results}

A total of 4268 men and 4946 women were included in the present study. The median BMI of the study population was $26 \cdot 2$ $\mathrm{kg} / \mathrm{m}^{2}$ in men and $24 \cdot 3 \mathrm{~kg} / \mathrm{m}^{2}$ in women (Table 1). The prevalence of overweight and obese individuals was approximately $64 \%$ for men and $44 \%$ for women. For both sexes, between 46 and $49 \%$ of energy was derived from carbohydrates, approximately $35 \%$ was derived from fat and $14 \%$ was derived from protein. For the intake of macronutrients with regard to energy intake, differences between men and women could be detected. Men had a lower intake of total carbohydrates as well of mono- and disaccharides in the percentage of energy intake compared to women. By contrast, a higher intake of total fat and MUFA in the percentage of energy intake could be detected for men. The intake of animal protein ( $\%$ of energy) was higher in men, whereas the intake of vegetable protein $(\%$ of energy) was higher in women.

The results of selected quantile regression estimates at the 5th, 25th, 50th, 75th and 95th quantiles for macronutrients including $t$-values are presented in Table 2 for men and in Table 3 for women. Full details of the quantile regression including $95 \%$ confidence intervals based on bootstrap standard errors are provided in Figs. 1 and 2.

In men, the intake of total carbohydrates was negatively associated with BMI at the higher BMI quantiles (Table 2 and Fig. 1). There was no association between the intake of mono-/disaccharides and BMI. Over all BMI quantiles in men, the intake of polysaccharides had a negative relationship with BMI; this was stronger in the higher BMI quantiles than in the lower and middle BMI quantiles.

In women, there was no association between the total intake of carbohydrates and BMI over all BMI quantiles (Table 3 and Fig. 2). The intake of mono- and disaccharides was negatively associated with BMI at the higher BMI quantiles, but there was no association at lower and middle BMI quantiles. For the polysaccharides, there was no association with BMI.

There were positive associations between BMI and the intake of total protein and animal protein over the entire BMI range in both sexes. In men, these associations were generally stronger at the higher BMI quantiles than at the lower and middle BMI quantiles (Fig. 1). In women, the positive association became stronger moving from the lowest range towards the upper tail of the BMI range (Fig. 2). For example, every $1 \%$ higher intake of energy from animal protein was associated with a $0.19 \mathrm{~kg} / \mathrm{m}^{2}$ higher BMI in men and 0.06 $\mathrm{kg} / \mathrm{m}^{2}$ higher BMI in women at the lowest BMI quantiles and with a $0.32 \mathrm{~kg} / \mathrm{m}^{2}$ higher BMI in men and $0.40 \mathrm{~kg} / \mathrm{m}^{2}$ higher BMI in women at the highest BMI quantiles. By contrast, there was a negative association between BMI and the intake of vegetable protein in both sexes. This negative association was shown in the lower and middle range of BMI in men and in the middle range of BMI in women. At the higher BMI quantiles for both sexes, there was no association of BMI with the intake of vegetable protein.

A negative association between the intake of total fat and BMI was observed at the lower BMI quantiles, but there was no association at the other quantiles. BMI was negatively associated with the intake of SFA at the lower and middle BMI quantiles, while no association was found at the higher BMI quantiles. The intake of MUFA was not associated with BMI in men and negatively associated with the lower BMI quantiles in women. There was no association between the intake of PUFA and BMI over the BMI quantiles in men, whereas a positive association was shown at the lower BMI range in women.

\section{Discussion}

In a previous publication of the NVS II data, predictors of BMI were investigated in German adults using quantile 
Table 1. Main characteristics of the study population according to sex

\begin{tabular}{|c|c|c|c|c|c|c|c|c|}
\hline \multirow[b]{2}{*}{ Variable } & \multicolumn{4}{|c|}{ Men $(n$ 4268) } & \multicolumn{4}{|c|}{ Women ( $n$ 4946) } \\
\hline & Mean & $\mathrm{SE}$ & Median & 5-95th percentiles & Mean & $\mathrm{SE}$ & Median & 5-95th percentiles \\
\hline Age (years) & $48 \cdot 7$ & 0.3 & $49 \cdot 0$ & $20 \cdot 0-74.0$ & $48 \cdot 2$ & 0.2 & $48 \cdot 0$ & $21 \cdot 0-73 \cdot 0$ \\
\hline Energy intake (kcal/d) & 2837 & $11 \cdot 7$ & 2675 & $1975-4242$ & 2148 & $7 \cdot 3$ & 2063 & 1512-3074 \\
\hline BMI $\left(\mathrm{kg} / \mathrm{m}^{2}\right)$ & $26 \cdot 5$ & 0.06 & $26 \cdot 2$ & $20 \cdot 6-33 \cdot 3$ & $25 \cdot 2$ & 0.07 & $24 \cdot 3$ & $19 \cdot 2-34 \cdot 1$ \\
\hline \multicolumn{9}{|l|}{ BMI classification (\%) ${ }^{\mathrm{a}}$} \\
\hline Normal-weight & $35 \cdot 4$ & & & & $54 \cdot 4$ & & & \\
\hline Overweight & $47 \cdot 3$ & & & & $28 \cdot 7$ & & & \\
\hline Obese & $16 \cdot 5$ & & & & $15 \cdot 0$ & & & \\
\hline \multicolumn{9}{|c|}{ Absolute intake of macronutrients ( $\mathrm{g} / \mathrm{d}$ ) } \\
\hline Total carbohydrates & 324 & 1.6 & 304 & $200-509$ & 262 & $1 \cdot 0$ & 251 & 167-394 \\
\hline Mono- and disaccharides & 157 & $1 \cdot 2$ & 140 & $65-301$ & 139 & 0.8 & 130 & $66-242$ \\
\hline Polysaccharides & 150 & 0.7 & 143 & $88-236$ & 114 & 0.5 & 110 & $66-175$ \\
\hline Total protein & 98 & 0.5 & 93 & $61-150$ & 73 & 0.3 & 71 & $48-108$ \\
\hline Animal protein & 61 & 0.4 & 56 & $30-102$ & 44 & 0.2 & 41 & $23-72$ \\
\hline Vegetable protein & 37 & 0.2 & 35 & $23-57$ & 30 & 0.1 & 28 & $19-46$ \\
\hline Total fat & 111 & 0.6 & 103 & $62-187$ & 82 & 0.4 & 77 & $47-132$ \\
\hline SFA & 51 & 0.3 & 46 & $25-89$ & 38 & 0.2 & 35 & $20-64$ \\
\hline MUFA & 37 & 0.2 & 34 & $20-63$ & 26 & 0.1 & 25 & $14-43$ \\
\hline PUFA & 17 & 0.1 & 15 & $9-30$ & 13 & 0.1 & 12 & $7-22$ \\
\hline Alcohol & 18 & 0.3 & 12 & $0-56$ & 6 & $0 \cdot 1$ & 3 & $0-23$ \\
\hline \multicolumn{9}{|c|}{ Relative intake of macronutrients (\% of energy) } \\
\hline Total carbohydrates & $46 \cdot 1$ & 0.12 & $45 \cdot 8$ & $33 \cdot 8-59 \cdot 5$ & $49 \cdot 4$ & $0 \cdot 11$ & $49 \cdot 3$ & $37 \cdot 4-61.5$ \\
\hline Mono- and disaccharides & $22 \cdot 1$ & 0.12 & $21 \cdot 2$ & $10 \cdot 5-36 \cdot 7$ & $26 \cdot 0$ & $0 \cdot 11$ & $25 \cdot 4$ & $14 \cdot 1-40 \cdot 2$ \\
\hline Polysaccharides & $21 \cdot 7$ & 0.08 & $21 \cdot 3$ & $14 \cdot 0-30 \cdot 8$ & $21 \cdot 7$ & 0.07 & 21.5 & $13 \cdot 5-30 \cdot 6$ \\
\hline Total protein & $14 \cdot 0$ & 0.04 & $13 \cdot 8$ & $10 \cdot 3-18 \cdot 2$ & 13.9 & 0.03 & $13 \cdot 8$ & $10 \cdot 2-17 \cdot 9$ \\
\hline Animal protein & $8 \cdot 6$ & 0.04 & 8.4 & $5 \cdot 1-12 \cdot 8$ & $8 \cdot 3$ & 0.03 & $8 \cdot 1$ & $4 \cdot 7-12 \cdot 5$ \\
\hline Vegetable protein & $5 \cdot 3$ & 0.02 & $5 \cdot 2$ & $3 \cdot 7-7 \cdot 3$ & $5 \cdot 6$ & 0.02 & $5 \cdot 5$ & $3 \cdot 9-7 \cdot 7$ \\
\hline Total fat & 35.5 & 0.11 & $35 \cdot 5$ & $24 \cdot 2-47 \cdot 1$ & $34 \cdot 6$ & $0 \cdot 10$ & 34.5 & $23 \cdot 9-45 \cdot 8$ \\
\hline SFA & $16 \cdot 1$ & 0.06 & $15 \cdot 8$ & $9 \cdot 9-23 \cdot 3$ & $15 \cdot 9$ & 0.06 & $15 \cdot 6$ & $10 \cdot 1-22 \cdot 7$ \\
\hline MUFA & $11 \cdot 7$ & 0.04 & $11 \cdot 7$ & $7 \cdot 7-16 \cdot 0$ & $11 \cdot 1$ & 0.04 & $11 \cdot 0$ & $7 \cdot 5-15 \cdot 3$ \\
\hline PUFA & $5 \cdot 4$ & 0.03 & $5 \cdot 1$ & $3 \cdot 2-8 \cdot 7$ & $5 \cdot 4$ & 0.03 & $5 \cdot 1$ & $3 \cdot 2-8 \cdot 8$ \\
\hline Alcohol & 4.4 & 0.07 & $3 \cdot 0$ & $0 \cdot 0-13 \cdot 6$ & $2 \cdot 1$ & 0.04 & 1.0 & $0.0-7 \cdot 6$ \\
\hline
\end{tabular}

Note: BMI, body mass index; SFA, saturated fatty acids; MUFA, monounsaturated fatty acids; PUFA, polyunsaturated fatty acids.

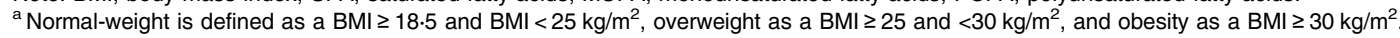

regression. The results indicated that energy intake was one of the most important predictors of BMI in participants who were overweight and obese, but not in those of normalweight ${ }^{(1)}$. The present study investigated whether macronutrients are associated with BMI, independent of energy intake and other predictors of BMI, and whether these associations vary along the BMI distribution. The results show a strong positive association of BMI with total protein intake, especially animal protein, over all BMI quantiles in both sexes. The intake of total carbohydrates was negatively associated with BMI in higher BMI ranges for men, but not for women. A weak negative association between the intake of total fat and BMI was observed only at the lower BMI quantiles in both men and women.

In previous studies, the mean values of macronutrient intake were compared between BMI categories. However, these

Table 2. Association between BMI and macronutrients at selected quantiles of the quantile regression (men, $n$ 4268)

\begin{tabular}{|c|c|c|c|c|c|c|c|c|c|c|}
\hline \multirow[b]{2}{*}{ Macronutrient (\% of energy) ${ }^{a}$} & \multicolumn{2}{|c|}{$\begin{array}{c}\text { 5th Quantile } \\
\left(\mathrm{BMl} 20.6 \mathrm{~kg} / \mathrm{m}^{2}\right)\end{array}$} & \multicolumn{2}{|c|}{$\begin{array}{l}\text { 25th Quantile } \\
\left(\mathrm{BMl} 23.8 \mathrm{~kg} / \mathrm{m}^{2}\right)\end{array}$} & \multicolumn{2}{|c|}{$\begin{array}{c}\text { 50th Quantile } \\
\left(\mathrm{BMI} 26 \cdot 2 \mathrm{~kg} / \mathrm{m}^{2}\right)\end{array}$} & \multicolumn{2}{|c|}{$\begin{array}{l}\text { 75th Quantile } \\
\left(\text { BMl } 28.9 \mathrm{~kg} / \mathrm{m}^{2} \text { ) }\right.\end{array}$} & \multicolumn{2}{|c|}{$\begin{array}{l}\text { 95th Quantile } \\
\text { (BMI } 33.3 \mathrm{~kg} / \mathrm{m}^{2} \text { ) }\end{array}$} \\
\hline & Estimate & $t$-value & Estimate & $t$-value & Estimate & $t$-value & Estimate & $t$-value & Estimate & $t$-value \\
\hline Total carbohydrates & -0.003 & -0.36 & -0.022 & $-2 \cdot 58$ & -0.021 & $-2 \cdot 79$ & $-0.041^{*}$ & $-4 \cdot 10$ & $-0.081^{*}$ & -4.69 \\
\hline Mono- and disaccharides & -0.010 & 1.07 & 0.003 & 0.36 & 0.002 & 0.32 & -0.006 & -0.54 & -0.049 & $-2 \cdot 89$ \\
\hline Polysaccharides & $-0.057^{\star}$ & $-4 \cdot 27$ & $-0.070^{*}$ & -5.46 & $-0.068^{*}$ & -6.09 & $-0.082^{*}$ & $-5 \cdot 26$ & $-0.111^{*}$ & -3.42 \\
\hline Total protein & $0 \cdot 109^{*}$ & 3.23 & $0.143^{*}$ & $5 \cdot 27$ & $0.148^{*}$ & $6 \cdot 16$ & $0 \cdot 181^{*}$ & $5 \cdot 37$ & $0.324^{*}$ & 5.99 \\
\hline Animal protein & $0.192^{*}$ & $6 \cdot 51$ & $0 \cdot 169^{*}$ & $6 \cdot 60$ & $0.206^{*}$ & 8.87 & $0.228^{*}$ & $7 \cdot 34$ & $0.344^{*}$ & $5 \cdot 61$ \\
\hline Vegetable protein & -0.156 & $-2 \cdot 12$ & $-0.264^{\star}$ & $-4 \cdot 30$ & $-0.266^{\star}$ & $-5 \cdot 34$ & $-0.291^{*}$ & -3.76 & -0.125 & -0.83 \\
\hline Total fat & $-0.026^{\star}$ & $-2 \cdot 81$ & -0.018 & -1.90 & -0.006 & -0.62 & -0.007 & -0.56 & 0.040 & 1.53 \\
\hline SFA & $-0.053^{*}$ & $-2 \cdot 86$ & $-0.067^{\star}$ & -3.94 & -0.040 & $-2 \cdot 67$ & -0.002 & -0.08 & -0.001 & 0.02 \\
\hline MUFA & -0.037 & -1.48 & 0.016 & 0.60 & 0.004 & 0.15 & 0.075 & $2 \cdot 30$ & 0.156 & 2.29 \\
\hline PUFA & 0.075 & 1.92 & 0.052 & 1.35 & 0.035 & 1.01 & 0.013 & 0.30 & 0.149 & 1.84 \\
\hline
\end{tabular}

Note: BMI, body mass index; SFA, saturated fatty acids; MUFA, monounsaturated fatty acids; PUFA, polyunsaturated fatty acids.

${ }^{a}$ Adjusted for age, sports activities, socioeconomic status, smoking habits, partner relationship status, self-reported health status and energy intake.

${ }^{*} P<0.005$ (Bonferroni corrected $P$-value 0.05/10). 
Table 3. Association between BMl and macronutrients at selected quantiles of the quantile regression (women, $n$ 4946)

\begin{tabular}{|c|c|c|c|c|c|c|c|c|c|c|}
\hline \multirow[b]{2}{*}{ Macronutrient ( $\%$ of energy) ${ }^{a}$} & \multicolumn{2}{|c|}{$\begin{array}{l}\text { 5th Quantile } \\
\left(\text { BMl } 19.2 \mathrm{~kg} / \mathrm{m}^{2}\right)\end{array}$} & \multicolumn{2}{|c|}{$\begin{array}{l}\text { 25th Quantile } \\
\left(\text { BMI } 21.8 \mathrm{~kg} / \mathrm{m}^{2} \text { ) }\right.\end{array}$} & \multicolumn{2}{|c|}{$\begin{array}{l}\text { 50th Quantile } \\
\left(\text { BMl } 24 \cdot 3 \mathrm{~kg} / \mathrm{m}^{2}\right)\end{array}$} & \multicolumn{2}{|c|}{$\begin{array}{l}\text { 75th Quantile } \\
\left(\text { BMI } 27.7 \mathrm{~kg} / \mathrm{m}^{2}\right)\end{array}$} & \multicolumn{2}{|c|}{$\begin{array}{l}\text { 95th Quantile } \\
\left(\text { BMI } 34.1 \mathrm{~kg} / \mathrm{m}^{2} \text { ) }\right.\end{array}$} \\
\hline & Estimate & $t$-value & Estimate & $t$-value & Estimate & $t$-value & Estimate & $t$-value & Estimate & $t$-value \\
\hline Total carbohydrates & 0.002 & 0.23 & 0.008 & 1.02 & -0.008 & -0.93 & -0.026 & $-2 \cdot 27$ & -0.030 & $-1 \cdot 17$ \\
\hline Mono- and disaccharides & 0.009 & 0.98 & 0.009 & 1.26 & 0.009 & 1.06 & -0.025 & $-2 \cdot 34$ & $-0.049^{\star}$ & $-3 \cdot 12$ \\
\hline Polysaccharides & -0.020 & -1.71 & -0.013 & $-1 \cdot 18$ & -0.034 & $-2 \cdot 62$ & -0.004 & -0.24 & 0.082 & $2 \cdot 28$ \\
\hline Total protein & 0.047 & 1.48 & $0.134^{*}$ & 5.94 & $0 \cdot 191^{*}$ & 6.93 & $0.274^{\star}$ & $7 \cdot 73$ & $0.331^{*}$ & 4.62 \\
\hline Animal protein & 0.064 & $2 \cdot 12$ & $0.136^{*}$ & $6 \cdot 10$ & $0.222^{*}$ & 8.29 & $0.300^{*}$ & 8.72 & $0.397^{\star}$ & 5.83 \\
\hline Vegetable protein & -0.109 & $-2 \cdot 48$ & $-0 \cdot 104$ & $-2 \cdot 25$ & $-0 \cdot 178^{*}$ & $-3 \cdot 40$ & -0.168 & $-2 \cdot 23$ & -0.041 & -0.23 \\
\hline Total fat & -0.013 & $-1 \cdot 21$ & $-0.029^{\star}$ & $-3 \cdot 28$ & -0.022 & $-2 \cdot 13$ & 0.012 & 0.94 & 0.017 & 0.59 \\
\hline SFA & -0.040 & $-2 \cdot 20$ & $-0.067^{\star}$ & $-4 \cdot 36$ & $-0.062^{*}$ & $-3 \cdot 60$ & 0.008 & 0.34 & -0.054 & -1.01 \\
\hline MUFA & -0.048 & $-1 \cdot 70$ & $-0.088^{\star}$ & $-3 \cdot 76$ & -0.055 & -1.97 & 0.036 & 1.04 & 0.008 & 0.09 \\
\hline PUFA & 0.039 & 0.99 & $0.083^{*}$ & $3 \cdot 11$ & 0.051 & $1 \cdot 34$ & $0 \cdot 110$ & $2 \cdot 35$ & 0.239 & $2 \cdot 69$ \\
\hline
\end{tabular}

Note: BMI, body mass index; SFA, saturated fatty acids; MUFA, monounsaturated fatty acids; PUFA, polyunsaturated fatty acids.

a Adjusted for age, sports activities, socioeconomic status, smoking habits, partner relationship status, self-reported health status and energy intake.

${ }^{*} P<0.005$ (Bonferroni corrected $P$-value 0.05/10).

approaches are not robust against outliers that have a large influence on the results. The statistical model of quantile regression provides more detailed information regarding the association between BMI and macronutrients along the BMI range than previous analyses based on mean values. By applying a quantile regression analysis, the results of the present study indicate that the association between BMI with macronutrients differs along the BMI range as well as within the same BMI category.

A number of studies have had inconsistent results regarding the association between BMI and intake of protein. Several population-based cross-sectional studies showed a positive association between BMI and protein intake $e^{(3,5,7,8)}$. In a Swedish population-based cross-sectional study of 1135 subjects, 36-61 years of age, Brandhagen et al. ${ }^{(3)}$ found that energy-adjusted total protein intake was positively associated with BMI in men, but not in women. Based on a crosssectional study of 6619 Italian subjects, 17-82 years of age, Randi et al. ${ }^{(5)}$ reported that BMI was positively associated with the proportion of energy from protein among women only. By contrast, a negative association of BMI with protein was observed by Pasiakos et al. ${ }^{(25)}$ when analysing data from the National Health and Nutrition Examination Survey, 2001-10 (n 23876 adults). Additionally, some intervention studies showed a negative association between protein intake and BMI, but in contrast to the results of the NHANES survey, they indicated that protein-rich diets have a short-term positive effect on weight loss, usually occurring over weeks or a few months with no long-term effects ${ }^{(26,27)}$.

By excluding underreporters of energy intake, using measured BMI data and considering the entire BMI distribution, the present study demonstrated that BMI is associated with
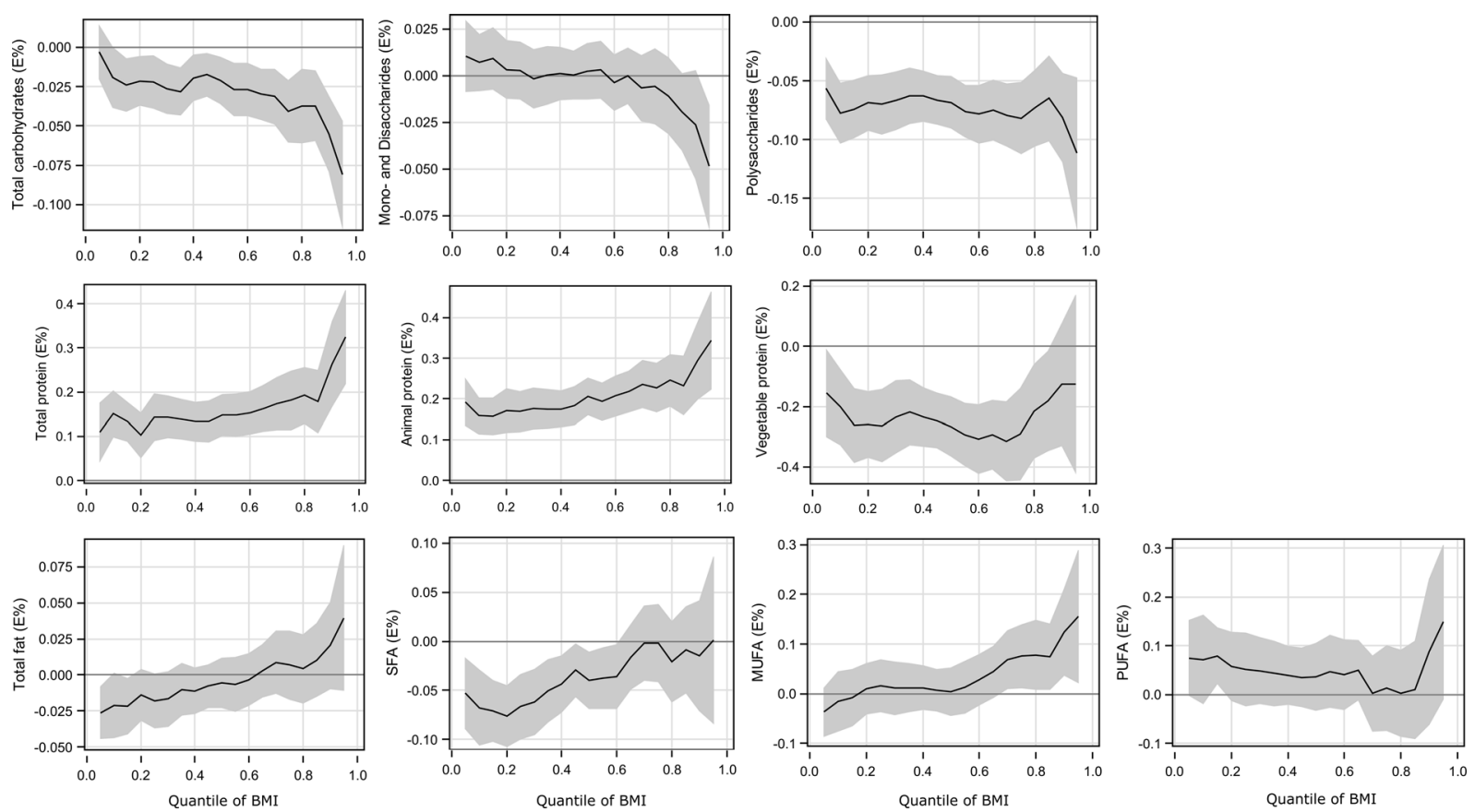

Fig. 1. Quantile regression estimation in men: macronutrients (\% of energy) and BMI. The solid line indicates the quantile regression estimates and the shaded area indicates the $95 \%$ confidence interval. BMI, body mass index; SFA, saturated fatty acids; MUFA, monounsaturated fatty acids; PUFA, polyunsaturated fatty acids. 

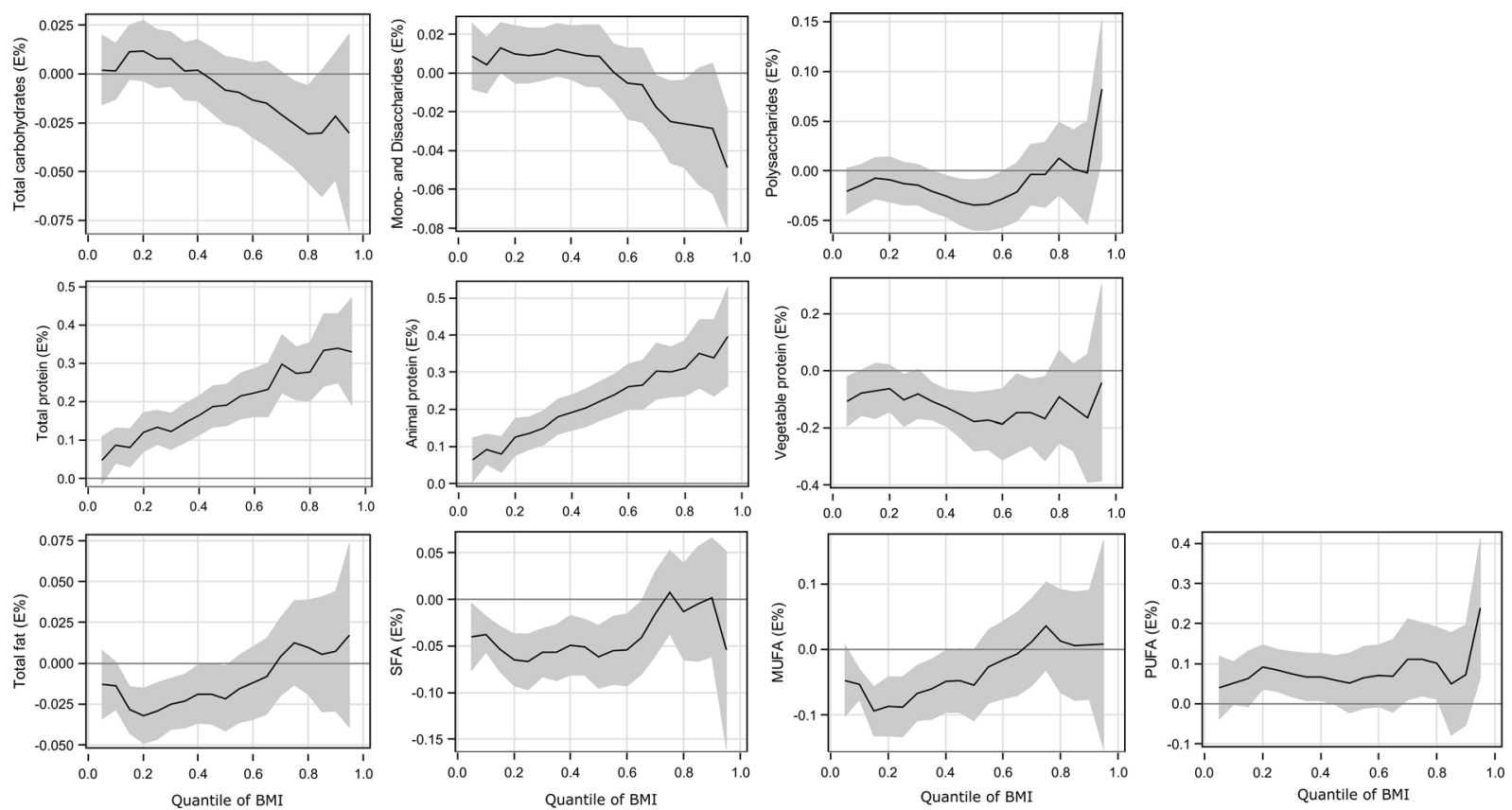

Fig. 2. Quantile regression estimation in women: macronutrients ( $\%$ of energy) and BMI. The solid line indicates the quantile regression estimates and the shaded area indicates the $95 \%$ confidence interval. BMI, body mass index; SFA, saturated fatty acids; MUFA, monounsaturated fatty acids; PUFA, polyunsaturated fatty acids.

the intake of protein in both men and women. In particular, a high intake of animal protein is most strongly associated with a high BMI in the overweight and obesity ranges. Further analysis revealed a comparable regression curve slope for the association of BMI with the consumption of meat and meat products, the main sources of animal protein in the NVS II participants (data not shown). This suggests that a high consumption of meat and meat products is strongly associated with overweight and obesity. This finding is supported by a longitudinal study of 21966 UK subjects, 20-69 years of age at baseline. Rosell et al. ${ }^{(8)}$ investigated changes in weight and BMI over a 5-year period in meat-eating, fish-eating, vegetarian and vegan men and women and found the largest weight gain in the meat-eaters and the smallest in the vegans. Alkerwi et al. ${ }^{(28)}$ showed that the consumption of animal protein, particularly that derived from meat products, was positively associated with BMI. Some more studies have shown that a greater risk of being overweight or obese is associated with higher intake of animal protein ${ }^{(5,29)}$. Additionally, results of the Belgian Food Consumption Survey 2004 (3083 participants, 15 years of age and older) and the Chicago Western Electric Study (2107 employed men aged 40-55 years at baseline in 1957-8) revealed inverse associations of vegetable protein intake and $\mathrm{BMI}^{(30,31)}$. Findings of the present study are that the intake of vegetable protein is also negatively associated with BMI, but not for obese men or for women in the higher overweight $\left(>27.7 \mathrm{~kg} / \mathrm{m}^{2}\right)$ and obesity ranges. These results could be explained by the lower vegetable protein intake of obese participants (data not shown).

A review of epidemiological studies concluded that most cross-sectional population studies found a negative association between carbohydrate intake and BMI in men as well as in women $^{(32)}$. In the present cross-sectional study, BMI was also negatively associated with intake of total carbohydrates in men, but not in women. This might be due to differences in the consumption of foods rich in carbohydrates between both sexes. Further analysis showed a similar regression curve slope for the association of BMI with the consumption of high-carbohydrate foods including bread, cereals and cereal products, potatoes and potato products and pastries (data not shown). In addition, different associations with the BMI for the single fractions of carbohydrates were also observed in the present study. A strong negative association of BMI with polysaccharides was shown over the entire BMI range, whereas no association between BMI and mono-/disaccharides was observed for men. For women, however, no clear association between BMI and single fractions of carbohydrates was observed. In a review by van Baak and Astrup ${ }^{(33)}$, it was summarised that there is insufficient evidence to draw any conclusion regarding the association between sugar and nonsugar carbohydrates and BMI.

By contrast, studies which investigated the association of carbohydrate intake and BMI over time have reported a positive association between the intake of total carbohydrates and $\mathrm{BMI}^{(9,10)}$. Riera-Crichton and Tefft conducted a time series analysis of the US population between 1974 and 2006, as well as a global panel of data surveys carried out in the years 2002, 2005 and 2010 in 164 countries, to estimate the contributions of changes in macronutrient intake to changes in population weight ${ }^{(10)}$. The analysis showed that the intake of carbohydrates was strongly and positively associated with population weight gain across countries. The results suggested that a $1 \%$ increase in carbohydrate intake, even when controlling energy intake, resulted in an approximate $1 \%$ increase in the prevalence of both overweight and obesity over 5 years. Likewise, data from NHANES I 1971-5 and NHANES 
2005-6 showed that independent of energy intake, the shift towards a higher percentage of energy from carbohydrates is associated with a higher prevalence of obesity ${ }^{(9)}$.

Many studies show inconsistencies with regard to the association between BMI and dietary fat intake. The US Prostate Cancer Prevention Trial, a cohort of 15266 middle-aged and elderly men, demonstrated that high energy intake from fat is associated with an increasing $\mathrm{BMI}^{(11)}$. By contrast, a population-based cross-sectional study in Sweden reported a negative association between BMI and fat intake in middle-aged $\operatorname{men}^{(3)}$. Using quantile regression analysis, Shankar ${ }^{(34)}$ found no association between BMI and the proportion of energy intake from total fat over all BMI quantiles among 3407 Chinese individuals aged $20-45$ years. In a systematic review and meta-analysis, Hooper et al. ${ }^{(35)}$ found that no clear conclusion could be made regarding the association of BMI and intake of fat in the general population. In the present investigation, only a weak negative association between total fat intake and BMI for normal-weight women could be shown. Furthermore, Melanson et al. ${ }^{(36)}$ concluded from a systematic review evaluating the effect of SFA, MUFA and PUFA intake on body weight that there was insufficient evidence supporting these associations. In the present study, SFA was the major fraction of fat (nearly half of total fat). Compared with the other fatty acids, SFA had the strongest association with BMI but mostly in the normal-weight range. The weak negative association of BMI with the intake of total fat and SFA in the normal-weight range in the present study was not expected. However, in the data analysis of the present study, energy intake and other predictors of BMI were considered. Therefore, these predictors could be more important than fat intake for the association with BMI.

The strength of the present study is the large sample size of the population data from the NVS II, which made it possible to exclude underreporters, to stratify for sex and to provide the statistical power to examine the association between BMI and intake of macronutrients across the BMI distribution. Precise body height and weight measurement data was also ensured in the analyses.

There are limitations in the present study. The analysis of the data from NVS II reflects the association between BMI and the intake of macronutrients only at that particular point in time. The cross-sectional design of the present study also does not allow drawing any conclusions about the causes that may underlie the associations. Further longitudinal studies considering the entire BMI range would be useful in this regard. Lastly, in this analysis, diet history interviews were used to estimate food consumption over the previous 4 weeks. This method is useful for the investigation of usual macronutrient intake over a longer period of time, but it requires a high level of cognitive skills on the part of the study participants to remember their food consumption over the previous 4 weeks. This could affect the estimates of energy and macronutrient intake and therefore attenuate the association with $\mathrm{BMI}^{(37)}$.

In conclusion, the results of the present cross-sectional study suggest that the association between BMI and the intake of macronutrients varies along the BMI range for German adults independent of energy intake and other predictors of BMI. The results also suggest that BMI is associated with a higher intake of animal protein in both sexes and a lower intake of polysaccharides in men. Further investigations are necessary to determine whether reducing the consumption of animal protein-rich foods and increasing the consumption of foods containing polysaccharides could contribute to a favourable weight status.

\section{Acknowledgments}

The authors thank Dr Paola Ferrario (Max Rubner-Institut, Department of Physiology and Biochemistry of Nutrition, Karlsruhe) for her statistical advice.

The NVS II was funded by the German Federal Ministry of Food and Agriculture. The Ministry had no role in the design, analysis or writing of this article.

K. M. was responsible for analysing and interpreting the data and writing the article; C. K. and T. H. were involved in study design, data interpretation and manuscript preparation and critically reviewed the manuscript; I. H. contributed to data interpretation, critically reviewed the manuscript and had primary responsibility for the final content. All authors read and approved the final version of the manuscript.

The authors declare that they have no conflict of interest.

\section{References}

1. Moon K, Krems C, Heuer T, et al. (2017) Predictors of BMI vary along the BMI range of German adults - results of the German National Nutrition Survey II. Obes Facts 10, 38-49.

2. German Nutrition Society, Austrian Nutrition Society, Swiss Nutrition Society (2019) Referenzwerte für die Näbrstoffzufubr (Reference Values for Nutrient Intake), 2nd ed., rev. Bonn: Umschau Buchverlag.

3. Brandhagen M, Forslund HB, Lissner L, et al. (2012) Alcohol and macronutrient intake patterns are related to general and central adiposity. Eur J Clin Nutr 66, 305-313.

4. Trichopoulou A, Gnardellis C, Benetou V, et al. (2002) Lipid, protein and carbohydrate intake in relation to body mass index. Eur J Clin Nutr 56, 37-43.

5. Randi G, Pelucchi C, Gallus S, et al. (2007) Lipid, protein and carbohydrate intake in relation to body mass index: an Italian study. Public Health Nutr 10, 306-310.

6. Shay CM, Van Horn L, Stamler J, et al. (2012) Food and nutrient intakes and their associations with lower BMI in middle-aged US adults: the International Study of Macro-/Micronutrients and Blood Pressure (INTERMAP). Am J Clin Nutr 96, 483-491.

7. Vinknes KJ, de Vogel S, Elshorbagy AK, et al. (2011) Dietary intake of protein is positively associated with percent body fat in middle-aged and older adults. $J$ Nutr 141, 440-446.

8. Rosell M, Appleby P, Spencer E, et al. (2006) Weight gain over 5 years in 21,966 meat-eating, fish-eating, vegetarian, and vegan men and women in EPIC-Oxford. Int J Obes 30, 1389-1396.

9. Austin GL, Ogden LG \& Hill JO (2011) Trends in carbohydrate, fat, and protein intakes and association with energy intake in normal-weight, overweight, and obese individuals: 1971-2006. Am J Clin Nutr 93, 836-843.

10. Riera-Crichton D \& Tefft N (2014) Macronutrients and obesity: revisiting the calories in, calories out framework. Econ Hum Biol 14, 33-49.

11. Satia-Abouta J, Patterson RE, Schiller RN, et al. (2002) Energy from fat is associated with obesity in U.S. men: results from the Prostate Cancer Prevention Trial. Prev Med 34, 493-501. 
12. Field AE, Willett WC, Lissner L, et al. (2007) Dietary fat and weight gain among women in the Nurses' Health Study. Obesity (Silver Spring) 15, 967-976.

13. Poslusna K, Ruprich J, de Vries JH, et al. (2009) Misreporting of energy and micronutrient intake estimated by food records and 24 hour recalls, control and adjustment methods in practice. Br J Nutr 101, Suppl. 2, S73-S85.

14. Spencer EA, Appleby PN, Davey GK, et al. (2002) Validity of selfreported height and weight in 4808 EPIC-Oxford participants. Public Health Nutr 5, 561-565.

15. Heuer T, Krems C, Moon K, et al. (2015) Food consumption of adults in Germany: results of the German National Nutrition Survey II based on diet history interviews. Br J Nutr 113, 1603-1614.

16. World Health Organization (2014) Obesity and overweight. http:// www.who.int/mediacentre/factsheets/fs311/en/ (accessed June 2020).

17. Mensink GBM, Haftenberger M \& Thamm M (2001) Validity of DISHES 98, a computerised dietary history interview: energy and macronutrient intake. Eur J Clin Nutr 55, 409-417.

18. Slimani N, Deharveng G, Charrondiere RU, et al. (1999) Structure of the standardized computerized 24-h diet recall interview used as reference method in the 22 centers participating in the EPIC project. Comput Meth Programs Biomed 58, 251-266.

19. Slimani N, Ferrari P, Ocke M, et al. (2000) Standardization of the 24-hour diet recall calibration method used in the European prospective investigation into cancer and nutrition (EPIC): general concepts and preliminary results. Eur J Clin Nutr 54, 900-917.

20. Hartmann BM, Heuer T \& Hoffmann I (2015) The German Nutrient Database: effect of different versions on the calculated energy and nutrient intake of the German population. J Food Compost Anal 42, 26-29.

21. Goldberg GR, Black AE, Jebb SA, et al. (1991) Critical evaluation of energy intake data using fundamental principles of energy physiology: 1. Derivation of cut-off limits to identify under-recording. Eur J Clin Nutr 45, 569-581.

22. Black AE (2000) Critical evaluation of energy intake using the Goldberg cut-off for energy intake:basal metabolic rate. A practical guide to its calculation, use and limitations. Int J Obes Relat Metab Disord 24, 1119-1130.

23. Müller MJ, Bosy-Westphal A, Klaus S, et al. (2004) World Health Organization equations have shortcomings for predicting resting energy expenditure in persons from a modern, affluent population: generation of a new reference standard from a retrospective analysis of a German database of resting energy expenditure. Am J Clin Nutr 80, 1379-1390.
24. Koenker R \& Hallock K (2001) Quantile regression. J Econ Perspect 15, 143-156.

25. Pasiakos SM, Lieberman HR \& Fulgoni 3rd VL (2015) Higher-protein diets are associated with higher HDL cholesterol and lower BMI and waist circumference in US adults. J Nutr 145, 605-614.

26. Westerterp-Plantenga MS, Nieuwenhuizen A, Tome D, et al. (2009) Dietary protein, weight loss, and weight maintenance. Annu Rev Nutr 29, 21-41.

27. Farnsworth E, Luscombe ND, Noakes M, et al. (2003) Effect of a high-protein, energy-restricted diet on body composition, glycemic control, and lipid concentrations in overweight and obese hyperinsulinemic men and women. Am J Clin Nutr 78, 31-39.

28. Alkerwi A, Sauvageot N, Buckley JD, et al. (2015) The potential impact of animal protein intake on global and abdominal obesity: evidence from the Observation of Cardiovascular Risk Factors in Luxembourg (ORISCAV-LUX) study. Publ Health Nutr 18, 18311838

29. Murtaugh MA, Herrick JS, Sweeney C, et al. (2007) Diet composition and risk of overweight and obesity in women living in the southwestern United States. I Am Diet Assoc 107, 1311-1321.

30. Lin Y, Bolca S, Vandevijvere S, et al. (2011) Plant and animal protein intake and its association with overweight and obesity among the Belgian population. Br J Nutr 105, 1106-1116.

31. Bujnowski D, Xun P, Daviglus ML, et al. (2011) Longitudinal association between animal and vegetable protein intake and obesity among men in the United States: the Chicago Western Electric Study. J Am Diet Assoc 111, 1150-1155.

32. Gaesser GA (2007) Carbohydrate quantity and quality in relation to body mass index. I Am Diet Assoc 107, 1768-1780.

33. van Baak MA \& Astrup A (2009) Consumption of sugars and body weight. Obes Rev 10, Suppl. 1, 9-23.

34. Shankar B (2010) Obesity in China: the differential impacts of covariates along the BMI distribution. Obesity (Silver Spring) 18, 16601666.

35. Hooper L, Abdelhamid A, Bunn D, et al. (2015) Effects of total fat intake on body weight. Cochrane Database Syst Rev 7, CD011834.

36. Melanson EL, Astrup A \& Donahoo WT (2009) The relationship between dietary fat and fatty acid intake and body weight, diabetes, and the metabolic syndrome. Ann Nutr Metab 55, 229-243.

37. Eisinger-Watzl M, Strassburg A, Ramunke J, et al. (2015) Comparison of two dietary assessment methods by food consumption: results of the German National Nutrition Survey II. Eur J Nutr $\mathbf{5 4}, 343-354$ 